\title{
Investigating the Impact of Alcohol Consumption on Some Haematological Variables among Alcohol Consumers in Jos Metropolis, Nigeria
}

\author{
Moses D Lugos ${ }^{1}{ }^{*}$, Bitrus N Lekshak ${ }^{2}$, Changjul L Singnap ${ }^{2}$, Umanka Y Polit ${ }^{1}$ and Benedict H Mangs ${ }^{3}$ \\ ${ }^{1}$ Department of Medical Laboratory Science, Faculty of Medical Sciences, University of Jos, Nigeria \\ ${ }^{2}$ Department of Haematology and Blood Transfusion, University of Jos, Nigeria \\ ${ }^{3}$ Department of Chemical Pathology, University of Jos, Jos-Nigeria
}

Received: September 24, 2018; Accepted:October 11, 2018; Published: October 12, 2018

*Corresponding author: Moses D Lugos, Department of Medical Laboratory Science, Faculty of Medical Sciences, University of Jos, Nigeria; Email: LugosM@UniJos.Edu.Ng

\begin{abstract}
Ethanol is contained in alcoholic beverages, which are produced by the process of fermentation of grains, fruits, and other sources of sugar. The effect of alcohol consumption among youths and adults resulting to escalating crime rate in the society has generated great concern. The impact of alcohol consumption on haematological variables has not been well documented in Jos metropolis. The study sought to establish whether alcohol consumption has any effect on the haematological status of individuals or not. Following informed consent, we determined haematocrit values by the microhaematocrit method, haemoglobin $(\mathrm{Hb})$ concentration by cyanmethaemoglobin technique, total and differential white blood cell counts (WBC), malaria parasite as well as microscopic blood film reporting of 124 alcohol consumers and 53 non-consumers as a control. SPSS version 23 was used to compare mean values between alcohol consumers and the control group (student t-test), while associations of blood film report were determined by chi-square. Results showed a significantly higher total lymphocytes count among alcohol consumers compared to nonalcohol consumers $(48.28 \pm 12.98 \mathrm{v} 41.91 \pm 11.59$; $\mathrm{p}=0.002)$. Also, the blood film reporting revealed a significantly higher percentages of macrocytes $(\mathrm{p}=0.001)$, microcytes $(\mathrm{p}=0.020)$, hypochromia $(\mathrm{p}=0.001)$, polychromasia $(\mathrm{p}=0.013)$, rouleaux formation $(\mathrm{p}=0.004)$ and atypical lymphocytes $(\mathrm{p}=0.011)$ and malaria parasitaemia $(\mathrm{p}=0.001)$ among alcohol consumers compared to the control group. Anisocytosis and hypochromia, which are essential characteristic features of anaemia, have been shown to associate with alcohol consumption. The implication is that excessive alcohol intake may impact adversely on haematological variables, and particularly constitute an increased risk of developing anaemia.
\end{abstract}

Keywords: Alcohol Consumption; Haematological Variables; Anisocytosis; Hypochromia

\section{Introduction}

An alcohol beverage is a drink containing ethanol, commonly known as alcohol. Alcoholic beverages are generally classified into three; the beer (bottled and local), wines and spirits [1]. These drinks are legally consumed in most countries, and over 100 countries have laws regulating their production, sale and consumption [2]. Studies have shown that people drink alcohol to enhance friendship, to increase power, to escape difficulties, to get drunk, for entertainment, or for ceremonial reasons, as well as to cope with stress and for social influences [3].

Excessive alcohol consumption has been linked to numerous adverse events, especially in impairing the state of the brain. [4, 5]. Alcohol abuse is fast becoming a public health concern among the Nigerian youths and adult strata of the society $[6,7]$.

Heavy intake of alcohol is a leading cause of preventable mortality, second only to cigarette smoking in industrialised countries [8]. Alcohol is implicated in more than $40 \%$ of all fatal traffic accidents in $25 \%$ of all general hospital admissions, in liver and upper gastrointestinal cancers, suicides sex crimes, industrial accidents, robbery, murder and fetal alcohol syndrome [9-11]. Conversely, there is evidence to suggest that moderate intake of alcohol has some advantages of reducing the risk of coronary heart disease and dementia, the leading causes of death in most affluent societies, especially in the elderly persons, [12, 13]. Therefore, it is expedient to unravel and make available to the public and research community, the benefit and harmful effects of alcohol consumption on specific haematological variables in our location.

With the global daily increase in the population of alcohol consumers, many scientific papers have been published on the subject of the biological effects of alcohol on the human body and from different parts of the world including some parts of Nigeria, but none has been reported from Jos metropolis in Plateau state, Nigeria.

This study was therefore designed to determine the effect of alcohol consumption on some haematological variables among alcohol consumers in Jos metropolis.

\section{Materials and Methods}

\section{Subject Selection}

After obtaining ethical clearance and informed written 
consent, a total of 177 subjects were recruited for this study, which comprised of 124 alcohol consumers (bottled beer and locally brewed burukutu, wine and gin or spirit) and 53 apparently healthy non-alcohol consumers that served as a control group. The alcohol consumers selected for this study refer to individuals who have been consistent consumers of alcohol for over seven (7) years, while non-consumers of alcohol are those who abstain from alcohol consumption for a minimum of five (5) years or from birth. All subjects were apparently healthy and between the ages of 20 and 85 years and resident within Jos metropolis.

\section{Study Design}

Questionnaires were administered to all the study subjects to establish whether they take alcohol or not. We also used the questionnaire to determine the type of alcoholic drinks taken by the alcohol consumers and how long they have been taking it and the frequency of intake. We collected blood samples from study subjects who consented to participate in the study. Individuals who did not grant consent to participate in the study were excluded.

\section{Sample Collection}

We collected $4.5 \mathrm{ml}$ of blood from each study participant into potassium EDTA anticoagulant bottles. The samples were analysed for Packed Cell Volume (haematocrit), hemoglobin concentration, total and differential white Cell Counts, as well as blood film reporting for cell morphology using standard manual methods.

\section{Laboratory Methodologies}

\section{Determination of haematocrit value by the microhaematocrit method}

To determine the value of packed cell volume (PCV), blood sample was well-mixed and drawn up to a 3/4th length of the plain capillary tube by capillary action. About $2 \mathrm{~mm}$ of the dry end of the capillary tube was sealed with plasticine and placed in the groove of the microhaematocrit centrifuge (ensured balance) Capillary tubes were centrifuged at 13,000 $\pm 2000 \mathrm{rpm}$ for 5 minutes. Hawksley haematocrit reader was used to read the value of haematocrit and was reported in percentage $(\%)[14,15]$.

\section{Haemoglobin ( $\mathrm{Hb}$ ) estimation by cyanmethaemoglobin method}

The cyanmethaemoglobin method was used to estimate the haemoglobin concentration of the study participants. In this method, the potassium ferricyanide ( $\mathrm{K} 3[\mathrm{Fe}(\mathrm{CN}) 6])$ present in the cyanmethaemoglobin reagent (Drabkin's solution) converts haemoglobin to methaemoglobin, while potassium cyanide (KCN) combines with methaemoglobin to form cyanmethaemoglobin, a stable color pigmentthatcan be quantified spectrophotometrically. The cyanmethaemoglobin method is briefly described: We pipetted $5 \mathrm{ml}$ of cyanmethaemoglobin reagent into the welllabelled test, and blank tubes. The blood sample was mixed, and $20 \mu \mathrm{l}$ was added to the test tube, while no sample was added to the reagent blank tube. The tubes were allowed to stand for 10 minutes at room temperature. The optical density (OD) of the test was read using spectrophotometer at $540 \mathrm{~nm}$ wavelength, zeroing with the blank. Haemoglobin concentration of test was estimated against the standard chart that was calibrated using the standard cyanmethaemoglobin solution. $\mathrm{Hb}$ value was reported in grams per decilitre (g/dl) [16].

\section{Total white blood cell count}

A 1:20 dilution of whole mixed blood in Turk's solution, which comprises of water (97): glacial acetic acid (2): gentian violet (1) lyses the red cells and stains the nuclei of white cells to be counted under the microscope. The method described: We added $20 \mu \mathrm{l}$ of well-mixed whole blood to $0.38 \mathrm{ml}$ of Turk's solution in a test tube, mixed and stood for 10 minutes. The cover glass was mounted on an improved Neuberger counting chamber until Newton's ring was observed. The improved Neuberger counting chamber was carefully charged with the well mixed diluted blood. The charged counting chamber was placed in a moist Petri dish for 10 minutes to allow white cells to settle into the same plane. After the 10 minutes of incubation, counting chamber was placed on the microscope stage and leucocytes were counted from the four corner squares using $10 \mathrm{x}$ objective observing margin rule. Total white cell count was calculated and expressed in 109/L [17].

\section{Differential white blood cell count and Blood Picture Assessment}

To examine and report the morphology of cells, a thin blood film was prepared and stained with Leishman's method. The stained blood film was allowed to air dry and examined using battlement method with oil immersion objective (x100). The blood film was scanned head to tail to report on morphological details of red blood cells, white blood cells and platelets. For differential white blood cell count, 100 consecutive white blood cells were counted taking note of the various types of leucocytes. They are counted, recorded and reported as percentages. Also, intracellular haemo-parasite, that is Plasmodium species was identified and reported $[17,18]$.

\section{Results}

Student t-test was used to compare the mean haematological variables between the test group (alcohol consumers) and the control subjects (non-consumers of alcohol) in order to determine the presence of significant difference in the parameters under consideration. A chi-squared $(\chi 2)$ test was used to compare for any difference in the categorical variables of film reporting between alcohol consumers and non-alcohol consumers. The statistical package, SPSS version 23.0 (SPSS, Inc., Chicago, IL, USA) was employed. Comparison for which $\mathrm{P}<0.05$ is consider significant.

The demographic data of the study population are presented in Table 1. There are no significant differences in the mean values of PCV, $\mathrm{Hb}$ and total WBC counts between subjects that consume alcohol and those who abstain from taking alcohol as reported in Table 2. The white blood cell differential count results are displayed in Table 3; alcohol consumers showed a significantly higher percentage lymphocyte count compared to non-alcohol consumers ( $48.28 \pm 12.98 \%$ v $41.91 \pm 11.59 \%$; $p=0.002$ ). Whereas, 
non-alcohol consumers had a borderline significant higher percentage neutrophil count compared to alcohol consumers (48.40 $\pm 12.70 \%$ v $44.50 \pm 13.67 \%$; $\mathrm{p}=0.078$ ).

Data from the film reporting in Table 4 revealed that a significantly higher percentage of alcohol consumers harbour malaria parasites in the blood compared to non-consumers (79.7\% v 20.3\%; $\mathrm{p}=0.001)$. Further results from the blood film reporting in Table 5, showed that significantly higher proportions of the following blood film variables were observed among alcohol consumers compared to non-consumers: macrocytes (80.4 v 19.6; $\mathrm{p}=0.001)$, microcytes (80.0 v 20.0; $\mathrm{p}=0.020)$, hypochromia ( $92.3 \mathrm{v} 7.7 ; \mathrm{p}=0.001)$, polychromasia ( $84.6 \mathrm{v} 15.4$; $\mathrm{p}=0.013)$, rouleaux formation $(77.8 \mathrm{v} 22.2 ; \mathrm{p}=0.004)$ and atypical lymphocytes $(90.0 \mathrm{v} 10.0 ; \mathrm{p}=0.011)$.

Table 1: Demographic variables of study participants

\begin{tabular}{|c|c|c|}
\hline variables & frequency & percentage $\%$ \\
\hline \multicolumn{3}{|l|}{ Gender } \\
\hline male & 99 & 55.9 \\
\hline female & 78 & 44.1 \\
\hline \multicolumn{3}{|l|}{ Alcohol Consumption } \\
\hline No & 53 & 29.9 \\
\hline \multicolumn{3}{|l|}{ Blood group } \\
\hline$A+$ & 32 & 20.4 \\
\hline $\mathrm{B}+$ & 38 & 24.2 \\
\hline $0+$ & 77 & 49 \\
\hline $\mathrm{AB}+$ & 4 & 2.5 \\
\hline A- & 3 & 1.9 \\
\hline $0-$ & 3 & 1.9 \\
\hline
\end{tabular}

Table 2: Comparison of mean haematological variables of alcohol and non-alcohol consumers

\begin{tabular}{|c|c|c|c|c|}
\hline \multirow[t]{2}{*}{ Haematological variables } & \multicolumn{2}{|c|}{ Status of alcohol consumption } & \multirow[t]{2}{*}{ t-test } & \multirow[t]{2}{*}{$P$ value } \\
\hline & consumers & Non-consumers & & \\
\hline $\operatorname{Pcv}(\%)$ & $44.93 \pm 4.43$ & $44.55 \pm 4.07$ & 0.536 & 0.593 \\
\hline $\mathrm{Hb}(\mathrm{g} / \mathrm{dl})$ & $14.65 \pm 1.63$ & $14.63 \pm 1.30$ & 0.063 & 0.95 \\
\hline $\mathrm{WBC}\left(\times 10^{9} / \mathrm{L}\right)$ & $5.84 \pm 2.30$ & $5.93 \pm 1.93$ & 0.264 & 0.806 \\
\hline
\end{tabular}

Table 3: Comparison of mean white blood cell differential counts of alcohol and non-alcohol consumers

\begin{tabular}{|c|c|c|c|}
\hline Differential white blood cell count & \multicolumn{2}{|c|}{ Status of alcohol consumption } & P value \\
\hline & consumers & $48.40 \pm 12.70$ & Non-consumers \\
\hline Neutrophils (\%) & $44.50 \pm 13.67$ & $41.91 \pm 11.59$ & 3.773 \\
\hline Lymphocytes (\%) & $48.28 \pm 12.98$ & $5.29 \pm 2.87$ & 0.078 \\
\hline Monocytes (\%) & $4.90 \pm 3.32$ & $5.48 \pm 4.69$ & 0.002 \\
\hline Eosinophils (\%) & $4.50 \pm 3.55$ & $1.40 \pm 0.38$ & 0.206 \\
\hline Basophils (\%) & $1.14 \pm 0.38$ & 0.968 & 0.356 \\
\hline
\end{tabular}


Table 4: Association between alcohol consumption and malaria parasitaemia

\begin{tabular}{|c|c|c|c|c|}
\hline \multirow[t]{2}{*}{ Malaria parasite } & \multicolumn{2}{|c|}{ Status of alcohol consumption } & \multirow[t]{2}{*}{$\chi^{2}$} & \multirow[t]{2}{*}{$P$ value } \\
\hline & Consumers & Non-Consumers & & \\
\hline Positive & $47(79.7)$ & $12(20.3)$ & 20.763 & 0.001 \\
\hline Negative & $77(65.3)$ & $41(34.7)$ & 10.983 & 0.001 \\
\hline Total & $124(70.1)$ & $53(29.9)$ & 28.48 & 0.001 \\
\hline
\end{tabular}

Table 5: Association between alcohol consumption and features from blood film reporting

\begin{tabular}{|c|c|c|c|c|}
\hline \multirow[t]{2}{*}{ Parameters } & \multicolumn{2}{|c|}{ Status of alcohol consumption } & \multirow[t]{2}{*}{$\chi^{2}$} & \multirow[t]{2}{*}{$P$ value } \\
\hline & Consumers & Non-Consumers & & \\
\hline Normal red cells & $45(56.3)$ & $35(43.8)$ & 1.25 & 0.264 \\
\hline Macrocytes & $45(80.4)$ & 11(19.6) & 20.643 & 0.001 \\
\hline Microcytes & $12(80.0)$ & $3(20.0)$ & 5.4 & 0.02 \\
\hline Hypochromia & $36(92.3)$ & $3(7.7)$ & 27.923 & 0.001 \\
\hline ovalocytes & $5(62.5)$ & $3(37.5)$ & 0.5 & 0.48 \\
\hline Crenated red cells & $16(66.7)$ & $8(33.3)$ & 2.667 & 0.102 \\
\hline Stomatocytes & $6(85.7)$ & $1(14.3)$ & 3.571 & 0.059 \\
\hline Spherocytes & $5(83.3)$ & $1(16.7)$ & 2.667 & 0.102 \\
\hline polychromasia & $11(84.6)$ & $2(15.4)$ & 6.231 & 0.013 \\
\hline Rouleaux formation & $21(77.8)$ & $6(22.2)$ & 8.333 & 0.004 \\
\hline Platelets Adequate & $107(69.5)$ & $47(30.5)$ & 23.377 & 0.001 \\
\hline Platelet increased & $6(75.0)$ & $2(30.5)$ & 2 & 0.157 \\
\hline Giant platelets & $7(53.8)$ & $6(46.2)$ & 0.077 & 0.782 \\
\hline Atypical lymphocytes & $9(90.0)$ & $1(10.0)$ & 6.4 & 0.011 \\
\hline
\end{tabular}

\section{Discussion}

The study was carried out to investigate the impact of alcohol intake on haematocrit value, haemoglobin concentration, total and differential white blood cell counts, film reporting of blood cells morphologies, and malaria parasites among alcohol consumers in comparison with non-alcohol consumers. This study was designed to test our hypothesis that states that alcohol consumption may be associated with deleterious effects on some haematological variables.

The demographic data of the study participants are presented in table 1. Table 2 showed that there was no statistically significant difference in the values of haematocrit, haemoglobin, and total white cell count among alcohol consumers compared to non-alcohol consumers. Since we did not classify the study subjects according to the rate and frequency of alcohol intake, this observation could not provide a clear picture of the impact of alcohol intake on these haematological variables.. We speculate that stratifying the study subjects according to the frequency and duration of alcohol consumption may reveal a clearer picture of the effect of excessive and prolonged alcohol intake on haematology. The results of the differential white blood cell counts presented in table 3 revealed that alcohol consumers had a significantly higher percentage of lymphocytes compared to nonconsumers of alcohol $(\mathrm{p}=0.002)$. Inversely, a higher percentage (at a borderline significance; $\mathrm{p}=0.078$ ) of the neutrophils count was reported among non-alcohol consumers compared to alcohol consumers. These reports have not been able to categorically decipher any advantege in the immune status of the two groups of the study participants. While the higher percentage of lymphocytes reported among alcohol consumers may be seen to confer potentials for adaptive immunity, the higher percentage neutrophil count seen among non-consumers of alcohol might be viewed as a potential for a stronger innate immune response..

As part of the thin blood film reporting, table 4 showed that alcohol consumers had a significantly higher incidence of malaria parasitaemia compared to non-consumers of alcohol $(\mathrm{p}=0.001)$.. It 
is contemplated that the increased malaria parasitaemia observed among the alcohol consumers could be associated with social habits such as keeping late nights at drinking spots and sleeping outside the mosquito nets among others, which increases their vulnerability to mosquito bites.. Interestingly, further blood film reporting presented in table 5 indicated increased incidences of macrocytes, microcytes, hypochromia, polychromasia, rouleaux formation and atypical lymphocytes among alcohol consumers compared to non-consumers of alcohol. These are common features that are characteristically oberved on blood films of patients suffering from some types of anaemia.

A study by Thoma and colleagues reported statistically decreased Hbconcentration, total white cell count and PCV among alcoholics in relation to increased alcohol consumption time [19]. A case-control study performed by Erhabor and colleagues in Nigeria had observed significant reduction in WBC, red cell count (RBC), haemoglobin, haematocrit and platelet count, while MCV values were significantly elevated [20].This report did not agree with our findings, although the mean values of $\mathrm{Hb}, \mathrm{WBC}$ and PCV recorded in this study was within a lower borderline and the time of alcohol consumption was not considered in the study. In a similar study by Elanchian et al, a statistically significant increased macrocytes among severe alcoholics was revealed in comparison to the non alcoholics [21]. The Elanchian finding is in agreement with data. The increased macrocytes among alcoholics could be associated with impaired dietary folate metabolism resulting to folate deficiency and leading to poor DNA development thereby releasing macrocytic cells into the peripheral blood circulation. A similar study by Yoganandh and colleagues reported grossly decreased level of both vitamin B12 and folate among severe alcoholics in comparison with non-alcoholic group [21].

The blood film report revealed statistically increased macrocytic, microcytic, hypochromic and polychromic red blood cells among the alcoholics. The blood film features suggest that alcohol consumption may be associated with anaemia, although the mean haematocrit and $\mathrm{Hb}$ values recorded in this study are at lower borderline. However alcohol consumption rate and duration should be consider because alcohol may have delay effect on haemaological parameters.

\section{Conclusions}

This study revealed a marked anisocytosis, and hypochromia among alcohol consumers and these are essential features of anaemia. The implication is that alcohol consumption associated with anaemia. These observations may be linked to poor dietary habit due to over-dependence on alcohol or its effect on absorption and utilization of essential vitamins required by the body. We recommend for a further study that will consider a more detailed historical data on alcohol consumers and stratify study participants to enhance understanding of the impact of alcohol intake on haematological variables. Furthermore, routine checks on haematological parameters may be necessary to avoid sudden onsets of haematological complications.

\section{Acknowledgements}

We want to use this opportunity to thank Mr Philip Jalo of the Intercountry Centre for Oral Health (ICOH) for Africa, Jos, Nigeria who assisted with the statistical analysis.

\section{References}

1. Giesbrecht, N, Ashley Wettlaufer, Emma Walker, Anca Ialomiteanu, Timothy Stockwell. Beer, wine and distilled spirits in Ontario: A comparison of recent policies, regulations and practices. Nordic Studies on Alcohol and Drugs. 2012;29(1):79-102.

2. Ferreira-Borges C, Esser MB, Dias S, Babor T, Parry CD. Alcohol control policies in 46 African countries: opportunities for improvement. Alcohol and alcoholism. 2015;50(4):470-476. doi: 10.1093/alcalc/ agv036

3. Abbey A, M J Smith and R O Scott. The relationship between reasons for drinking alcohol and alcohol consumption: An interactional approach. Addictive behaviors. 1993;18(6):659-670.

4. Mukamal KJ, Kuller LH, Fitzpatrick AL, Longstreth WT, Mittleman MA, Siscovick DS. Prospective study of alcohol consumption and risk of dementia in older adults. Jama. 2003;289(11):1405-1413.

5. Brust JC. Ethanol and cognition: indirect effects, neurotoxicity and neuroprotection: a review. International journal of environmental research and public health. 2010;7(4):1540-1557. doi: 10.3390/ ijerph7041540

6. Akanni E, Victor O Mabayoje, TO Zakariyahu, DP Oparinde. Haematological characterization among heavy alcohol consumers in Osogbo metropolis. Research Journal of Medical Sciences. 2010;4(2):48-52.

7. Obiechina G and B Isiguzo. Curbing the Menace of Drug Use among Secondary School Students in Nigeria. European Journal of Research and Reflection in Educational Sciences. 2016;4(1):1-64.

8. Mokdad AH, Marks JS, Stroup DF, Gerberding JL. Correction: actual causes of death in the United States, 2000. Jama. 2005;293(3): 293294.

9. Kannel WB. Alcohol and cardiovascular disease. Proceedings of the Nutrition Society. 1988;47(2):99-110.

10. Ifeanyi O, Omeh Yusuf Ndukaku, OT Ndubuisi, BL Eze Obioma. Some Haematological and Biochemical Parameters of Chronic Alcoholics in Umuahia, Abia State, Nigeria. Res J Pharmaceut Biol Chem Sci. 2014;5(2):831-836.

11. Llerena S, María Teresa Arias-Loste, Angela Puente, Joaquín Cabezas, Javier Crespo and Emilio Fábrega. Binge drinking: Burden of liver disease and beyond. World journal of hepatology. 2015;7(27):27032715. doi: 10.4254/wjh.v7.i27.2703

12. Klatsky AL. Moderate drinking and reduced risk of heart disease. Alcohol Research and Health. 1999;23(1):15-23.

13. Sabia S, Aurore Fayosse, Julien Dumurgier, Aline Dugravot, Tasnime Akbaraly, Annie Britton, Mika Kivimäki, et al. Alcohol consumption and risk of dementia: 23 year follow-up of Whitehall II cohort study. Bmj. 2018;362:k2927.

14.Bull BS. Procedure for determining packed cell volume by the microhematocrit method; approved standard. NCCLS Document H7A3. 2000;20(18):1-18. 
15. Dacie J and S Lewis. Practical Hematology. 10th Ed, Churchill Living Stone. 2006.

16. Kalaivani $\mathrm{K}$ and $\mathrm{P}$ Ramachandran. Time trends in prevalence of anaemia in pregnancy. Indian Journal of Medical Research. 2018; 147(3):268 -277. doi: 10.4103/ijmr.IJMR_1730_16

17. Lorenzo C, AJ Hanley and SM Haffner. Differential white cell count and incident type 2 diabetes: the Insulin Resistance Atherosclerosis Study. Diabetologia. 2014;57(1):83-92. doi: 10.1007/s00125-013-3080-0

18. Bain BJ, I Bates and MA Laffan. Dacie and Lewis Practical Haematology E-Book. Elsevier Health Sciences. 2016.
19. Thoma E, Sonila Bitri, Klodeta Mucaj, Andrin Tahiri and Irida Pano. Changes of some blood count variables in correlation with the time of alcohol abuse. J Addict Res Ther. 2015;6:2. doi: 10.4172/21556105.1000221

20.Erhabor 0 and Teddy Charles Adias. Evaluation Of Haematological Parameters Among Alcoholics In Port Harcourt Nigeria. International Journal of Laboratory Hematology. 2013;35:49-50.

21. Yoganandh T, S Mayilsamy and S Radhakrishnan. Comparison of haematological parameters between alcoholics and nonalcoholics. International Journal of Research in Medical Sciences. 2017;5(11):5041-5047. doi:http://dx.doi.org/10.18203/2320-6012. ijrms20174967 